\title{
QUALIDADE AMBIENTAL DE NASCENTE EM ÁREA URBANA
}

\section{ENVIRONMENTAL QUALITY OF WATER SOURCE IN URBAN AREA}

\section{Adir Silvério Cembranel \\ Engenheiro Ambiental. Professor Adjunto \\ Universidade Tecnológica Federal do Paraná - UTFPR. E-mail: adircembranel@utfpr.edu.br}

\section{Telmo Josiel Teles}

Acadêmico do Curso de Engenharia Ambiental Universidade Tecnológica Federal do Paraná UTFPR. E-mail: telmotelles@gmail.com

\section{Claudia Eugênia Castro} Bravo

Licenciatura em Biologia, Professor Associado Universidade Tecnológica Federal do Paraná UTFPR. E-mail: claudiacastro@utfpr.edu.b Ivane Benedetti Tonial

Licenciatura em Química, Professor Associado Universidade Tecnológica Federal do Paraná UTFPR. E-mail: ivane@utfpr.edu.br

\section{RESUMO}

As nascentes são importantes recursos no desenvolvimento econômico e social de uma localidade. No entanto, a qualidade da água da nascente está relacionada ao uso e ocupação do solo na área de contribuição. A ocupação urbana provoca alterações no ambiente, que podem causar desequilíbrio e comprometer a qualidade dos recursos hídricos. Neste sentido, o presente estudo avaliou a qualidade da água de uma nascente localizada no perímetro urbano do município de Francisco BeltrãoPR, por meio de análises físico-químicas, microbiológicas, toxicológicas, além de análise ambiental macroscópica. Os parâmetros físico-químicos analisados foram: temperatura; $\mathrm{pH}$; condutividade elétrica; turbidez; DQO; DBO e fósforo. Nas análises microbiológicas foram avaliados Coliformes Totais, Coliformes Termotolerantes e $E$. coli, utilizando a técnica de membrana filtrante. Nos ensaios de toxicidade aguda foi realizado o teste de imobilidade/mortalidade com o bioindicador Artemia salina. Na avaliação ambiental da nascente foi utilizada metodologia de abordagem macroscópica, por meio de análises qualitativas. Os parâmetros físico-químicos condutibilidade elétrica, DQO e DBO não atenderam os limites da legislação. As análises microbiológicas indicaram a presença de Coliformes Termotolerantes e E. coli. A análise de toxicidade indicou toxicidade da água. A análise macroscópica demonstrou péssimas condições de preservação da nascente.

Palavras-chave: Toxicidade. Microbiológica. Macroscópica. Água. Uso do solo.

\section{ABSTRACT}

Water source are important resources in the economic and social development of a locality. However, the quality of water source is related to the use and occupation of the soil in the area of contribution. Urban occupation causes changes in the environment, which can cause imbalance and compromise the quality of water resources. In this sense, the present study evaluated the water quality of a water source located in the urban perimeter of the municipality of Francisco Beltrão-PR, through physical-chemical, microbiological, toxicological analyzes, as well as macroscopic environmental analysis. The physical-chemical parameters analyzed were: temperature; $\mathrm{pH}$; electric conductivity; turbidity; DQO; DBO and phosphorus. In the microbiological analyzes, were evaluated Total Coliforms, Thermotolerant Coliforms and E. coli using the filter membrane technique. In the acute toxicity tests, the immobility/mortality test was performed with the bioindicator Artemia salina. In the environmental evaluation of the source was used macroscopic approach methodology, through qualitative analysis. The physicalchemical parameters electrical conductivity, DQO and DBO did not meet the limits of the legislation. Microbiological analyzes indicated the presence of thermotolerant coliforms and E. coli. Toxicity analysis indicated water toxicity. The macroscopic analysis showed poor conditions of spring preservation.

Keywords: Toxicity. Microbiological. Macroscopic. Water. Use of soil. 
Revista Tecnologia e Ambiente, v. 25, 2019, Criciúma, Santa Catarina/SC ISSN Eletrônico 2358-9426 e ISSN Impresso 1413-8131

\section{INTRODUÇÃO}

As nascentes são importantes recursos no desenvolvimento econômico e social de uma localidade. No entanto, a qualidade da água da nascente está diretamente relacionada ao uso e cobertura do solo na área de contribuição (ZANIN et al., 2013).

A forma de ocupação da área urbana provoca alterações no ambiente, que podem favorecer o desequilíbrio e comprometer a qualidade dos recursos hídrico desde as suas nascentes (BELIZÁRIO, 2015).

No Brasil, embora as nascentes sejam consideradas áreas de preservação permanente, (Lei 12.651/2012) (BRASIL, 2012), seu entorno limitante (50 m), muitas vezes acaba sendo desrespeitado, comprometendo a qualidade por meio da poluição, provocando o soterramento e extinção destas fontes. De acordo com Tucci (2008), a urbanização causa impactos negativos na qualidade da água de uma bacia hidrográfica, gerados especialmente pela falta de tratamento de esgoto, aumento das áreas impermeáveis, ocupação do leito de inundação ribeirinha e a deposição de resíduos sólidos urbanos de maneira incorreta.

A legislação brasileira, por meio da Resolução no 357 do Conselho Nacional do Meio Ambiente - CONAMA (BRASIL, 2005), estabelece parâmetros e índices na classificação das águas doces, e define seus usos, que podem ser utilizados para classificar as águas de uma nascente. Aliada a Resolução do CONANA, a Portaria 2.914/2011 do Ministério da Saúde determina parâmetros de qualidade da água para o consumo humano, por meio dos Valores Máximos Permissíveis (VMP) (BRASIL, 2011).

Dentre os parâmetros frequentemente avaliados encontram-se a Demanda Química de Oxigênio (DQO); Demanda Bioquímica de Oxigênio (DBO) e Oxigênio dissolvido (OD), os quais estão diretamente relacionados com a presença de matéria orgânica presentes nos cursos d'água. A turbidez é outro parâmetro de relativa importância na avaliação de um corpo hídrico, pois, corresponde à fração de matéria suspensa na água (argila, silte, plâncton, microorganismo, etc.) que é influenciada pelo regime de chuvas da região e pelas características geológicas (BRAGA, 2014).

O fósforo também deve ser considerado na avaliação, por se tratar de um macronutriente e relacionar-se ao desenvolvimento da biota aquática, sendo, ainda responsável pela eutrofização de ecossistemas aquáticos (ROCHA; MARTIN, 2005).

Além dos parâmetros relatados acima, para o consumo de água de nascente, é necessária a avaliação microbiológica, cuja presença pode estar relacionada a excrementos de animais (FIGUEIREDO, 2013; DANELUZ; TESSARO, 2015).

Os testes de toxicidade vêm para contribuir na avaliação e indicação de toxidade da água. Os testes utilizando A. salina como organismo indicador são úteis, baratos e de fácil execução e podem 
ser utilizados para análise preliminar da toxicidade das amostras. Testes mais específicos são recomendados para determinar a existência de substâncias tóxicas na água (FIGUEIREDO et al., 2013).

Os bioensaios utilizados para analisar a toxicidade de amostras de água, podem ser considerados como uma alternativa complementar as análises físico-químicas, uma vez que muitos destas análises não são capazes de detectar certas toxinas, bem como o efeito que eles causam nos organismos, sendo este o objetivo principal destes testes (RODRIGUES, 2012).

Neste sentido, o presente estudo teve como objetivo avaliar a qualidade da água de uma nascente localizada no perímetro urbano do município de Francisco Beltrão-PR, por meio de análises físico-químicas, microbiológicas e toxicológicas, além de análise ambiental macroscópica da nascente.

\section{MATERIAIS E MÉTODOS}

\subsection{Caracterização da área de estudo}

O estudo foi realizado em uma nascente, no perímetro urbano do município de Francisco Beltrão, localizado na região Sudoeste do Estado do Paraná (Figura 1). O município possui área de $735,113 \mathrm{~km}^{2}$ e população de 88.465 . A rede de coleta de efluente doméstico atende $65,3 \%$ das residências do município (IBGE, 2017).

A região apresenta clima subtropical mesotérmica úmida, $\mathrm{Cfb}$ segundo a classificação de Köeppen, está inserida no Bioma Mata Atlântica em uma zona de transição entre a Floresta Ombrófila Mista e Floresta Estacional Semidecidual (IBGE, 2010).

Figura 1 - Localização do município de Francisco Beltrão - PR

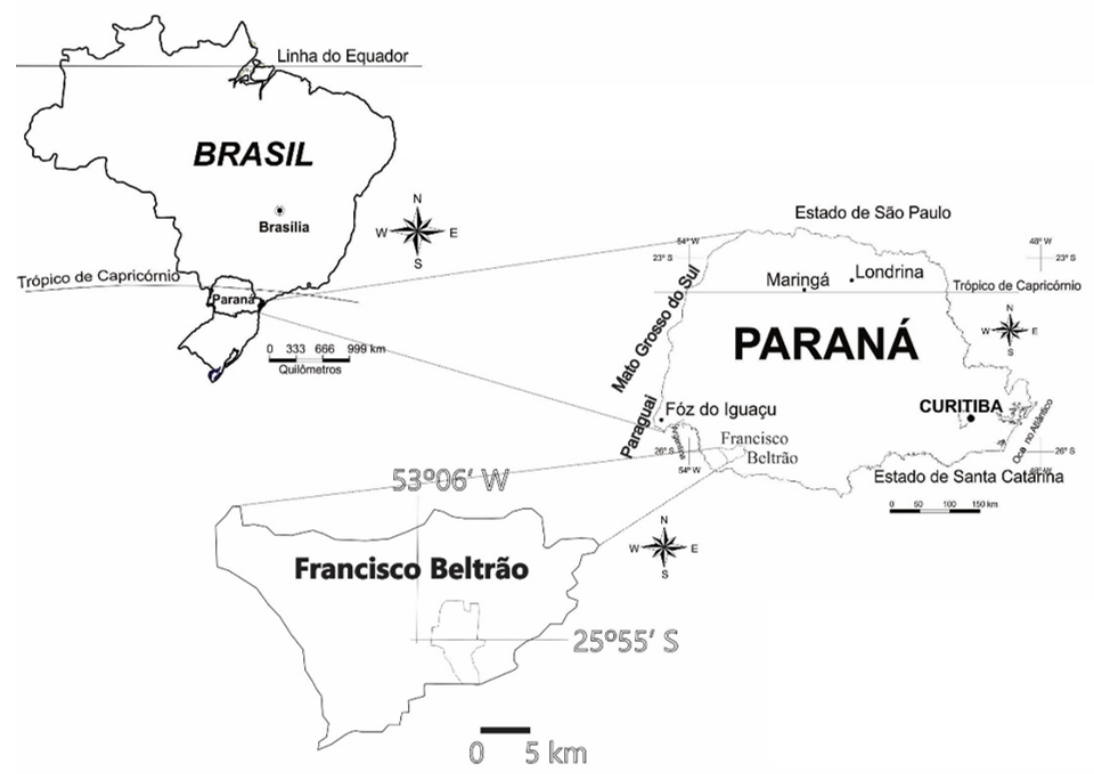

Fonte: IBGE, adaptado por Francischett (2018). 
A nascente localiza-se em loteamento habitacional urbano, localizado nas coordenadas $26^{\circ} 03^{\prime} 38^{\prime \prime} \mathrm{S}$ e $53^{\circ} 01^{\prime} 50^{\prime \prime} \mathrm{O}$. O empreendimento contém 180 lotes com área média de $450 \mathrm{~m}^{2}$ cada. A área foi adquirida no ano de 2012, antes da aquisição a área pertencia a zona rural e era utilizada em atividades agropecuárias (Figura 2).

Figura 2 - Imagem multitemporal da área de estudo

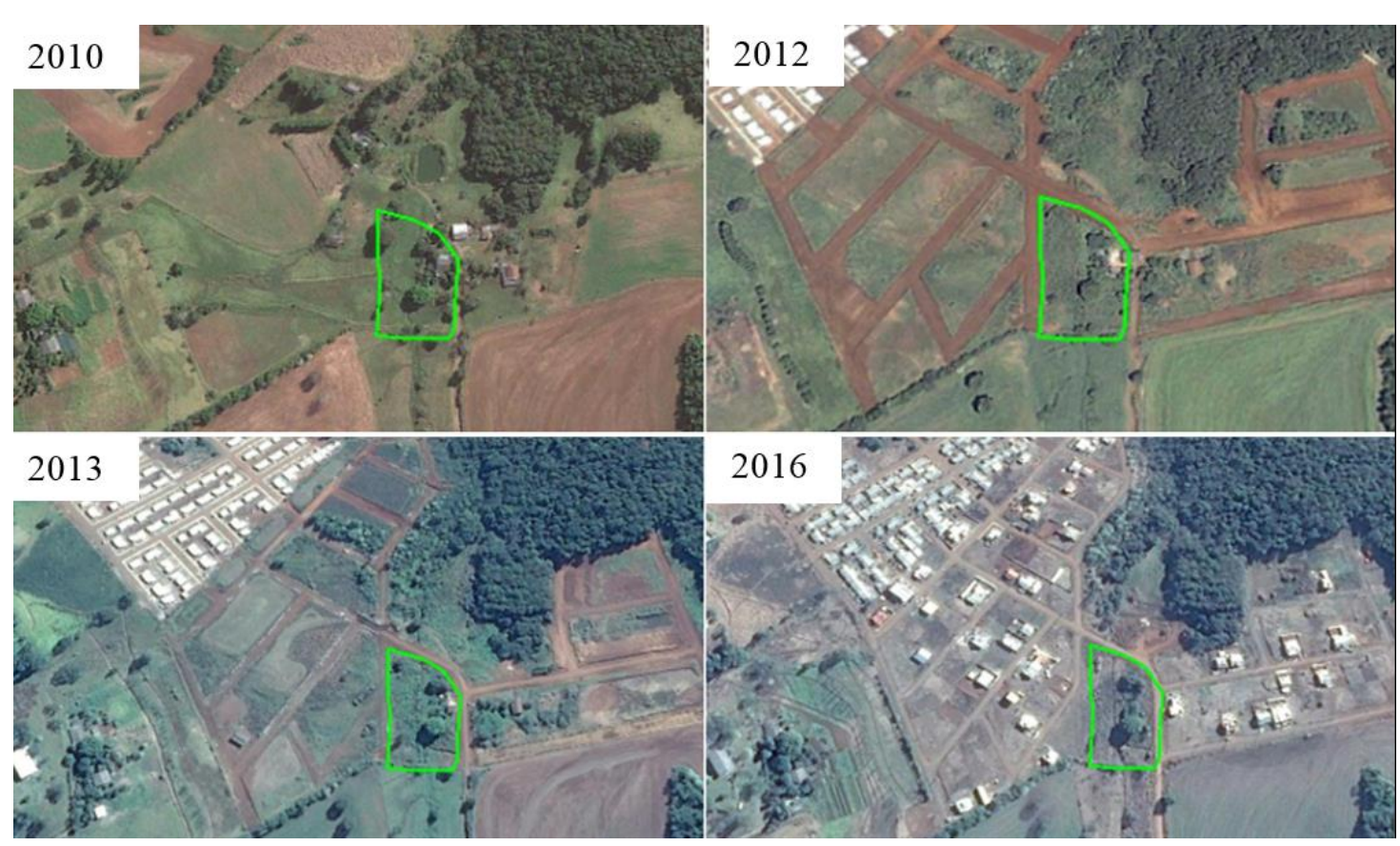

Fonte: Google Earth (2018). Adaptado pelos autores

No ano de 2012 foram executadas obras de infraestrutura no loteamento, como abertura de ruas, sistema de drenagem de águas pluviais, divisão de lotes e pavimentação. Com o início obras ocorreram os primeiros impactos negativos ao ambiente local, como a exposição e erosão do solo, supressão da vegetação nativa entre outros (Figura 2).

$\mathrm{Na}$ execução do loteamento, manteve-se uma área de aproximadamente dois hectares, destinada à reserva legal, de acordo com a legislação. O loteamento é interciso por um córrego de água permanente, além da nascente, os quais foram estabelecidos como Áreas de Preservação Permanente (APP), de acordo com o Código Florestal (Figura 3). 
Figura 3 - Caracterização da área de estudo

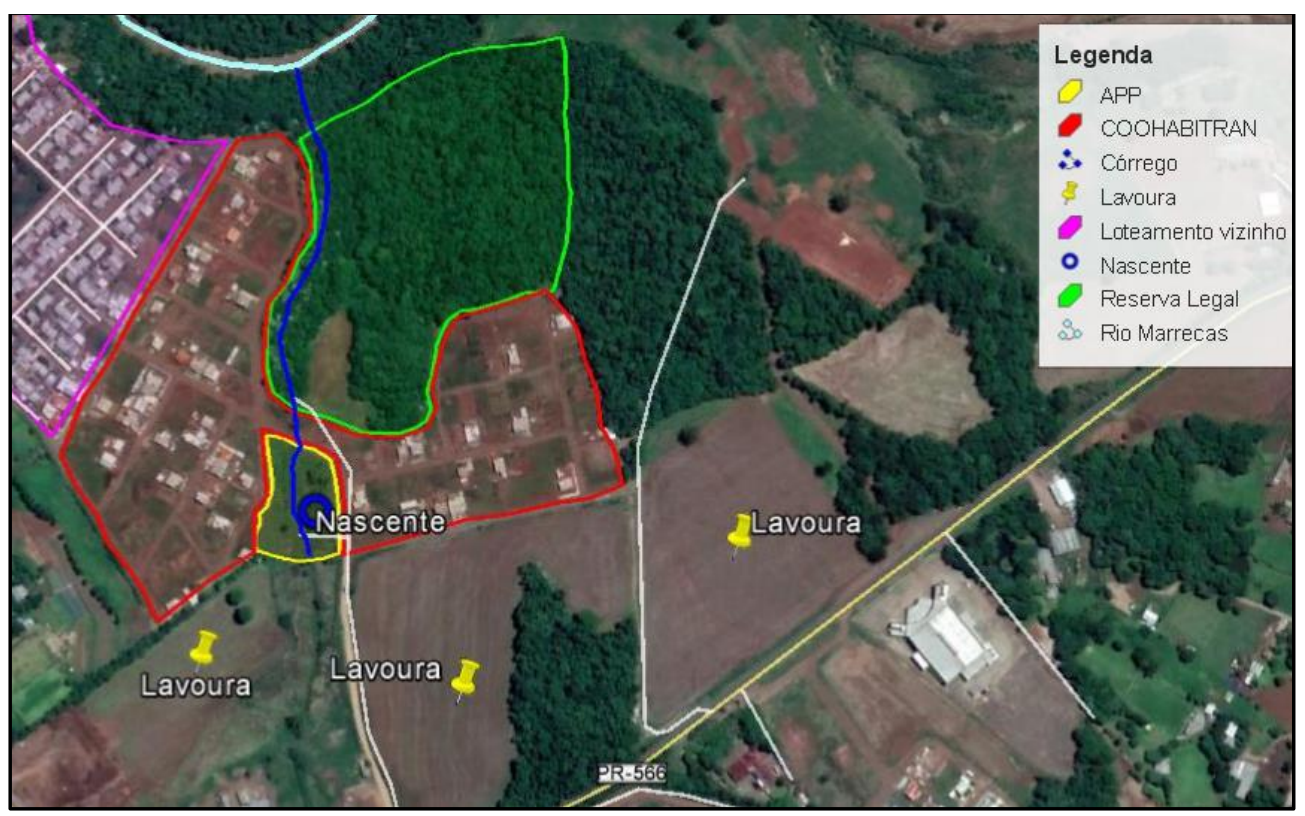

Fonte: Google Earth (2018). Adaptado pelos autores

A APP encontra-se em estado de abandono, servindo de depósito de resíduos, favorecendo a proliferação de animais peçonhentos, possibilitando a contaminação da nascente. Atualmente o loteamento conta com aproximadamente 400 habitantes, o qual não contempla sistema de coleta e tratamento de esgoto sanitário, sendo o efluente doméstico destinado às fossas sépticas.

\subsection{Análises físico-químicas}

Para caracterização físico-química da água da nascente foram realizadas quatro coletas de dois litros cada. As coletas ocorreram no mês de abril de 2018 (C1) e no mês de maio de 2018 três coletas (C2, C3 e C4).

Os parâmetros físico-químicos analisados foram: temperatura; $\mathrm{pH}$; condutividade elétrica; turbidez; demanda química de oxigênio (DQO); demanda bioquímica de oxigênio (DBO) e fósforo.

A determinação da temperatura foi efetuada in loco com o auxílio de um termômetro de mercúrio e as demais análises realizadas em triplicata no Laboratório de Águas e Efluentes, da Universidade Tecnológica Federal do Paraná - Campus Francisco Beltrão. Todas as análises foram realizadas conforme metodologias descritas no "Standard Methods" (APHA, 1998). Os dados das análises foram submetidos a análise estatística descritiva com utilização do software Excel.

$\mathrm{O}$ pH foi determinado pelo método eletrométrico (pHmetro marca MS Tecnopon, modelo mPA) conforme metodologia descrita na NBR 14339 (ABNT, 1999).

A condutividade elétrica foi determinada pelo método potenciométrico (condutivímetro, marca MS Tecnopon, modelo mCA 150P), conforme metodologia descrita na NBR 14340 (ABNT, 
Revista Tecnologia e Ambiente, v. 25, 2019, Criciúma, Santa Catarina/SC ISSN Eletrônico 2358-9426 e ISSN Impresso 1413-8131

1999). O oxigênio dissolvido (OD), turbidez, fósforo total, DQO e DBO foram determinados de acordo com os métodos estabelecidos pelo Standard Methods (APHA, 1998).

\subsection{Análises microbiológicas}

Na realização das análises microbiológicas da água foram realizadas duas coletas de amostras de água da nascente de um litro cada. As duas coletas ocorreram no mês de maio de 2018 (M1 e M2) de acordo com Standard Methods (APHA, 1998).

$\mathrm{Na}$ avaliação dos Coliformes Totais, Coliformes Termotolerantes e Escherichia coli, utilizouse a técnica de membrana filtrante, conforme metodologia proposta por APHA (2017).

\subsection{Análise de toxicidade - Artemia salina $\mathbf{L}$}

Nos ensaios de toxicidade aguda foram coletadas duas amostras de água de dois litros cada. As coletas ocorreram no mês de maio de 2018 (T1 e T2) de acordo com Standard Methods (APHA, 1998).

O teste de imobilidade/mortalidade com Artemia salina L. foi conduzido pelo método proposto por Guerra (2001), com modificações baseadas na ABNT NBR 13373. Inicialmente cistos de A. salina foram incubados em solução de sal marinho sintético (30 g/L), aerados, com luminosidade e temperatura de $25^{\circ} \mathrm{C}$, para induzir sua eclosão.

Após a eclosão dos cistos, 10 náuplios do microcrustáceo foram transferidos para poços de placas de cultivo, contendo: $2 \mathrm{~mL}$ da solução salina (controle negativo salino), $2 \mathrm{~mL}$ da água mineral (controle negativo doce), $2 \mathrm{~mL}$ das amostras em solução salina nas seguintes concentrações: 100\%, $50 \%, 25 \%, 12,5 \%, 6,2 \%$ e $3,1 \%$.

Foram realizadas quatro repetições para o controle negativo salino bem como para o controle negativo doce. Nas diluições da amostra em solução salina foram realizadas triplicatas e, após 24 horas de incubação, a $25^{\circ} \mathrm{C}$ e ao abrigo da luz, então realizada a contagem do número de náuplios mortos, considerados como tal aqueles que permaneceram imóveis durante 20 segundos de observação. A análise estatística foi feita através do Teste de Tukey $(\alpha=0,05 ; n=4)$, pelo programa GraphPad InStat (GRAPHPAD SOFTWARE INC, 2018).

\subsection{Análise ambiental macroscópica da nascente}

$\mathrm{Na}$ avaliação das condições ambientais da nascente foi utilizada a metodologia de abordagem macroscópica, proposta por Gomes et al. (2005), que adota critérios de avaliação qualitativa de possíveis impactos ambientais, aos quais são atribuídos valores, em que a soma total indicará a qualidade da nascente em termos macrocópicos. 
Os parâmetros foram identificados e avaliados in loco de forma visual qualitativa, considerando: Cor e odor da água; Resíduos acumulados ao seu entorno, Materiais Flutuantes, presença; espumas e óleo, lançamento de Esgoto, presença de emissários e sua distância da nascente; vegetação; presença de animais; uso antrópico; proteção da nascente; residências; estabelecimentos comerciais e indústrias. A partir da somatória dos valores da qualificação de impactos ambientais obtém-se o Índice de Impacto Ambiental em Nascentes.

\section{RESULTADOS E DISCUSSÕES}

\subsection{Análises físico-químicas}

A Tabela 1 apresenta os parâmetros físico-químicos (média \pm Desvio padrão) de amostras de água da nascente e os limites dos parâmetros estabelecidos na legislação.

Tabela 1 - Resultado dos parâmetros físico-químicos

\begin{tabular}{cccccc}
\hline Parâmetro & Média \pm DP & Máximo & Mínimo & $\begin{array}{c}\text { Portaria MS } \\
\mathbf{2 . 9 1 4 / 2 0 1 1}\end{array}$ & $\begin{array}{c}\text { CONAMA } \\
\text { 357/2005 }\end{array}$ \\
\hline $\mathrm{pH}$ & $6,13 \pm 0,37$ & 6,60 & 5,73 & 6,00 a 9,50 & 6,00 a 9,00 \\
\hline Temperatura & $20,90 \pm 1,42$ & $22,60{ }^{\circ} \mathrm{C}$ & $19,50{ }^{\circ} \mathrm{C}$ & NSA & NSA \\
\hline $\mathrm{CE}(\mathrm{S} / \mathrm{cm})$ & $148,2 \pm 1,265$ & 150,00 & 147,00 & NSA & NSA \\
\hline OD $\left(\mathrm{mg} / \mathrm{L} \mathrm{O}_{2}\right)$ & $4,63 \pm 0,55$ & 5,20 & 4,15 & NSA & $>5 \mathrm{mg} / \mathrm{L} \mathrm{O}_{2}$ \\
\hline Turbidez $(\mathrm{UNT})$ & $4,40 \pm 1,96$ & 6,64 & 1,86 & Até 1,0 & Até 100 \\
\hline DQO $\left(\mathrm{mg} / \mathrm{L} \mathrm{O} ~_{2}\right)$ & $50,85 \pm 14,10$ & 69,62 & 36,00 & NSA & NSA \\
\hline DBO $\left(\mathrm{mg} / \mathrm{L} \mathrm{O}_{2}\right)$ & $7,50 \pm 2,08$ & 10,26 & 5,30 & NSA & Até 5,00 \\
\hline FT $(\mathrm{mg} / \mathrm{L})$ & $0,030 \pm 0,012$ & 0,045 & 0,020 & NSA & Até 0,030 \\
\hline
\end{tabular}

CE: Condutividade Elétrica; OD: Oxigênio Dissolvido; FT: Fósforo Total; DP: Desvio Padrão; NSA: Não se aplica.

Os índices de pH da água da nascente, depende das relações entre a matéria orgânica, rochas, ar, água e os seres vivos que a cerca (ALVES et al., 2008). Os índices de pH encontrados na água da nascente apresentaram valor médio de acordo com o estabelecido nas legislações. No entanto, o valor mínimo encontrado em uma das amostras $(5,73)$ foi abaixo do valor mínimo determinado na Portaria $n^{\circ} 2.914$ (BRASIL, 2011) e na Resolução CONAMA nº 357 (BRASIL, 2005) (Tabela 1).

Os valores de $\mathrm{pH}$ abaixo do preconizado pela legislação podem estar associados a decomposição da matéria orgânica presente nas amostras (ALVES et al., 2008). De acordo com Medeiros et al. (2006) valores de $\mathrm{pH}$ muito básicos (maiores que 8,0) podem vir a solubilizar agentes tóxicos, como por exemplo amônia, metais pesados, sais de carbonato, entre outros enquanto que 
valores muito baixos (menores que 6,0) tornam a água ácida e acabam interferindo nas concentrações de dióxido de carbono, ácido carbônico, entre outros.

A temperatura apresentou variação $\left(19,50{ }^{\circ} \mathrm{C}-22,60{ }^{\circ} \mathrm{C}\right)$, que de acordo com a CETESB (2009) as variações da temperatura são decorrentes do regime climático, e corpos de água naturais apresentam variações sazonais e diurnas, bem como estratificação vertical. Além disso, a temperatura superficial é influenciada por fatores como latitude, altitude, estação do ano, período do dia, taxa de fluxo e profundidade.

A Resolução CONAMA no 357 (BRASIL, 2005) não utiliza a temperatura na classificação dos corpos hídricos. No entanto, o parâmetro é amplamente utilizado para avaliar a qualidade da água. De acordo com Sperling (2005) é natural a temperatura da água variar dentro do limite de $0{ }^{\circ} \mathrm{C}$ a 30 ${ }^{\circ} \mathrm{C}$, considerando o regime climático e a estação do ano de cada região. A fauna e a flora aquática possuem limites de tolerância térmica, necessitam de temperaturas adequadas para crescimento, migração e reprodução.

A condutividade elétrica consiste na capacidade do meio líquido conduzir corrente elétrica, devido aos íons dissolvidos, os quais são influenciados pela área de drenagem, geologia e regime pluviométrico (MACEDO, 2006). As amostras de água da nascente, avaliadas, apresentaram valores que variaram de $147 \mu \mathrm{S} / \mathrm{cm}$ a $150 \mu \mathrm{S} / \mathrm{cm}$.

A condutividade elétrica não é um parâmetro contemplado pela Portaria 2.914 (BRASIL, 2011) e na resolução CONAMA no 357 (BRASIL, 2005), porém, é amplamente utilizado em análises de qualidade da água, devido à associação que possui com os sólidos totais dissolvidos (minerais) (BAHIA et al., 2011), podendo estar associada à presença de substâncias com capacidade de condução elétrica, sendo que valores superiores a $100 \mu \mathrm{S} / \mathrm{cm}$ indicam ambientes impactados (CETESB, 2009). Toledo e Nicolella (2002) avaliaram a qualidade da água em pontos com diferentes tipos de uso e ocupação do solo e obtiveram resultados de condutividade elétrica variando entre 27 $\mu \mathrm{S} / \mathrm{cm}$ e $68,9 \mu \mathrm{S} / \mathrm{cm}$, sendo inferiores às observadas neste estudo.

Os valores de oxigênio dissolvido presente nas amostras de água, demonstraram pequena variação, entre 4,15 mg/L de $\mathrm{O}_{2}$ e 5,20 mg/L de $\mathrm{O}_{2}$. O ecossistema aquático necessita de oxigênio dissolvido para realizar trocas gasosas e manter o ecossistema ativo, pois é o principal elemento no metabolismo de microrganismos aeróbios. As concentrações de oxigênio podem estar relacionadas com temperatura, pressão e salinidade da água (MACHADO, 2006).

A concentração mínima de OD observado na água da nascente, encontra-se abaixo do preconizado pela legislação $\left(5 \mathrm{mg} / \mathrm{L}\right.$ de $\mathrm{O}_{2}$ ) para corpos hídricos Classe 2 (BRASIL, 2005), o que pode indicar a presença de matéria orgânica (MO). De acordo com Silva et al. (2009), a adição de MO nos cursos d'água consome oxigênio, por meio da oxidação química e da bioquímica para 
depuração da matéria orgânica. Concentrações semelhantes foram relatados por Almeida (2004) no monitoramento da qualidade microbiológica do córrego Ribeirão dos Porcos, que obteve valores de OD entre 4,57 a $5,96 \mathrm{mg} / \mathrm{L}$ de $\mathrm{O}_{2}$

Os valores de turbidez variaram de 1,86 UNT até 6,64 UNT. Tal variação pode ser justificada pelo regime de chuva, pois a área de preservação onde está localizada a nascente recebe toda a água de escoamento superficial, carreando inúmeros poluentes e detritos oriundos de processos erosivos (GOMES, 2005). Segundo Tucci (2208), a falta de tratamento de esgoto, o aumento de áreas impermeáveis e a deposição de resíduos incorretos potencializam este processo.

A turbidez corresponde à fração de matéria suspensa na água, é influenciada pelo regime de chuvas e pelas características geológicas. Geralmente, estão associados à turbidez em águas naturais fragmentos de argila, silte, plâncton, microrganismo e matéria, orgânica e inorgânica (BRAGA, 2014). A turbidez pode interferir na incidência de luz, impossibilitando algumas atividades fisiológicas dos microrganismos (LIBÂNIO, 2010).

Quando comparados a Resolução CONAMA no 357 (BRASIL, 2005), que estabelece limite máximo de turbidez de 100 UNT, os valores das amostras foram baixos. Porém, o padrão de potabilidade da Portaria n ${ }^{\circ} 2.914$ do Ministério da Saúde (BRASIL, 2011) estabelece limite máximo de 1 UNT, desta forma, nem mesmo o valor mínimo encontrado para este parâmetro encontra-se dentro do limite preconizado.

A DQO da água da nascente apresentou índices que variaram entre 36,00 mg/L O $\mathrm{O}_{2}$ a 69,62 $\mathrm{mg} / \mathrm{L} \mathrm{O}_{2}$. Essa variação pode ser decorrente de fatores como comportamento hidrológico, e lançamento de efluentes domésticos e agrícolas (VASCO et al., 2011).

A resolução do CONAMA n 357 (BRASIL, 2005), bem como a Portaria $n^{\circ} 2.914$ do MS (BRASIL, 2011), não estabelecem limites de DQO. Embora não possua valores previstos por lei, autores como Chapman e Kimstach (1996) definem que para águas superficiais não poluídas, o valor máximo de DQO é de 20,00 mg/L de $\mathrm{O}_{2}$. No entanto, autores como Tozzo e Gonçalves (2014) encontraram valores superiores no riacho Japira, localizado no município de Apucarana-PR, com índices entre 64,03 e $640,30 \mathrm{mg} / \mathrm{L}$ de $\mathrm{O}_{2}$, evidenciando que o manancial teve sua qualidade deteriorada pela urbanização.

As concentrações de DBO das amostras variaram entre 5,30 e 10,26 mg/L de $\mathrm{O}_{2}$, valores superiores ao preconizado pela legislação $\left(5,00 \mathrm{mg} / \mathrm{L}\right.$ de $\left.\mathrm{O}_{2}\right)$ para corpos hídricos de Classe II (BRASIL, 2005). De acordo com Machado (2006), águas superficiais com DBO inferiores a 4 mg/L de $\mathrm{O}_{2}$, são consideradas razoavelmente limpas, e aquelas com níveis maiores do que $10 \mathrm{mg} / \mathrm{L}$ de $\mathrm{O}_{2}$ são consideradas poluídas. Desta forma, o valor máximo do parâmetro encontrado na água da nascente, pode indicar contaminação. 
De acordo com (CETESB, 2009), valores elevados de DBO podem indicar presença de matéria orgânica no corpo hídrico, decorrentes, na maioria das vezes de escoamento superficial das áreas de loteamento e áreas agrícolas, potencializada pela degradação da área de APP (BORGES, 2003; GOMES, 2005).

A Resolução CONAMA n. 357 (BRASIL, 2005) estabelece como quantidade máxima de fósforo $0,03 \mathrm{mg} / \mathrm{L}$. Desta forma o valor médio de fósforo na nas amostras de água da nascente atendem o estabelecido na resolução. No entanto, o valor máximo encontrado no presente estudo (Tabela 1) ultrapassa o estabelecido, indicando uma contribuição para o processo de eutrofização (CETESB, 2009).

\subsection{ANÁLISES MICROBIOLÓGICAS}

Os parâmetros microbiológicos (Coliformes Totais, Coliformes termotolerantes e E. coli) apresentaram resultados positivos na água da nascente, estando em desacordo com o padrão de potabilidade definido pela Portaria $n^{\circ} 2.914$ (BRASIL, 2011), desqualificando a utilização desta água sem tratamento prévio. Mostrando-se em conformidade com a Resolução CONAMA $\mathrm{n}^{\circ} 357$ (BRASIL, 2005) que estabelece valores menores que 1000 Unidades Formadoras de Colônias em 100 $\mathrm{mL}$ de amostra (Tabela 2).

Tabela 2 - Resultado das análises para o parâmetro coliformes

\begin{tabular}{ccccc}
\hline \multirow{2}{*}{$\begin{array}{c}\text { Parâmetro } \\
\text { (UFC/ 100mL) }\end{array}$} & M1 & M2 & $\begin{array}{c}\text { Portaria } \\
\text { MS 2.914/2011 }\end{array}$ & \begin{tabular}{c} 
CONA \\
\cline { 2 - 5 }
\end{tabular} \\
Coliformes Totais & 220 & 170 & Aus $/ 100 \mathrm{~mL}$ & - \\
\hline Coliformes Termotolerantes & 35 & 30 & Aus $/ 100 \mathrm{~mL}$ & $<1000$ \\
\hline Escherichia coli & 34 & 29 & Aus $/ 100 \mathrm{~mL}$ & - \\
\hline
\end{tabular}

UFC: Unidade Formadora de Colônia. Aus: Ausência

Fonte: Autores (2018)

Os resultados encontrados indicam que a água da nascente pode ter sido contaminada possivelmente por ação antrópica, com manejo inadequado de fossas sépticas. Como o loteamento não é atendido pelo sistema de coleta e tratamento de esgoto, este efluente é armazenado em fossas sépticas, podendo contaminar águas subterrâneas, evidenciado pela presença de E. coli (SPERLING, 2005).

De acordo com a CETESB (2009), a E. coli é um microrganismo de origem exclusivamente fecal, estando presente, em densidades elevadas nas fezes de humanos, mamíferos e pássaros, sendo raramente encontrada na água ou solo que não tenham recebido contaminação fecal (CETESB, 2009). 
A presença desses organismos na água pode estar associada a excrementos de animais, uma vez que a área onde a fonte se encontra não está isolada e recebe grande contribuição pluvial do loteamento e de área agrícola vizinha (FIGUEIREDO, 2013; DANELUZ; TESSARO, 2015).

Resultados positivos para estes microorganismos também foram relatados por Daneluz e Tessaro (2015) em estudo realizado na área rural do município de Dois Vizinhos - PR, em água de poços e nascentes.

\subsection{ANÁLISE DE TOXICIDADE - Artemia salina L.}

O CONAMA por meio da Resolução n 396/2008, Artigo 13, Inciso 4º , regulamenta que testes de toxicidade podem ser empregados para determinar a qualidade de um manancial, uma vez que estas análises auxiliam na avaliação da qualidade do recurso (BRASIL, 2008).

O Teste de Tukey, com nível de 5\% de significância, indicou que o número de organismos mortos em cada tratamento $(50 \%, 25 \%, 12,5 \%, 6,2 \%$ e $3,1 \%)$ variou em comparação ao tratamento com $100 \%$ de concentração da água da nascente. Indicando que a água analisa apresentou-se tóxica ao bioindicador A. Salina de acordo com metodologia proposta por Guerra (2001).

Na Figura 4 pode-se observar que quanto maior a concentração da amostra de água da nascente, as quais os microcrustáceos foram expostos, maior a média de mortalidade dos bioindicador, demonstrando que as amostras oferecem características distantes as necessárias para a sua sobrevivência.

Para Dezotti et al. (2008) a A. salina evidencia a toxicidade aguda das amostras, referente ao efeito que agentes podem causar a organismos vivos, efeito este que se manifesta rapidamente e de forma severa.

Figura 4 -Organismos mortos em cada tratamento

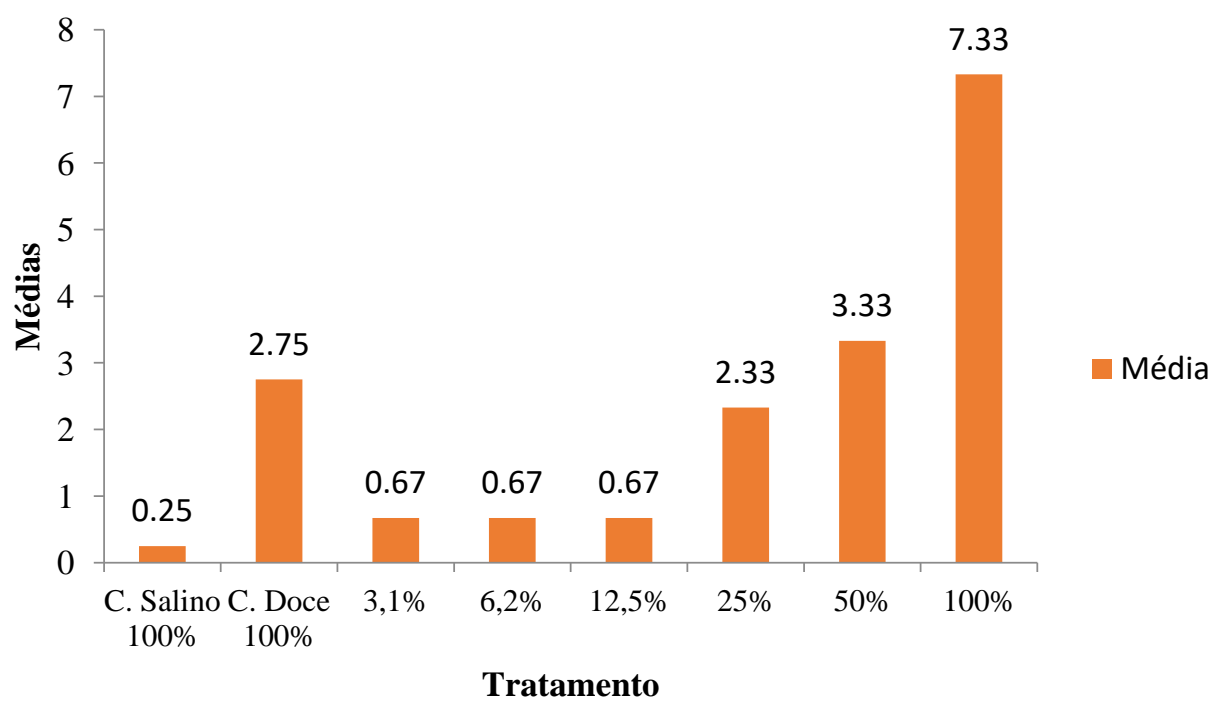

Fonte: Autores (2018) 


\subsection{ANÁLISE MACROSCÓPICA}

A análise qualitativa dos parâmetros macroscópicos da nascente esta apresentada na Tabela

3.

Tabela 3 - Quantificação da análise dos parâmetros macroscópicos da nascente

\begin{tabular}{cc}
\hline Parâmetros & Pontuação \\
\hline Cor da água & 2 (clara) \\
\hline Odor & 2 (cheiro fraco) \\
\hline Resíduos ao redor & 1 (muito) \\
\hline Resíduos na água & 2 (pouco) \\
\hline Espumas & 2 (pouco) \\
\hline Óleos & 2 (pouco) \\
\hline Esgoto & 3 (não há) \\
\hline Vegetação (Preservação) & 1 (alta degradação) \\
\hline Uso por animais & 1 (presença) \\
\hline Uso por humanos & 1 (presença) \\
\hline Proteção do local & 1 (fácil acesso) \\
\hline Proximidade com residências & 2 (entre 50 e $100 \mathrm{~m})$ \\
\hline Tipo de área de inserção & 3 (área protegida) \\
\hline SOMÁTÓRIO & $\mathbf{2 3}$ \\
\hline
\end{tabular}

Fonte: Autores (2018).

Foram avaliados os parâmetros: cor da água; odor; espumas e óleos. A cor da água apresentouse clara com certa quantidade de material em suspensão e baixo odor (cheiro fraco), podendo estar associado a matéria orgânica em decomposição. A presença de espumas e óleos na superfície da água ocorreu com pouca incidência. Estas condições que podem estar relacionadas ao escoamento superficial de água da chuva, uma vez que a área de proteção permanente no entorno da nascente não está consolidada. O escoamento superficial carrega inúmeros poluentes, pesticidas, óleo lubrificante, material orgânico, comprometendo a qualidade ambiental do recurso hídrico (GOMES, 2005).

A degradação ambiental está diretamente ligada ao uso e ocupação do solo, que impacta o ambiente de diferentes formas. O uso do solo diversifica-se a partir de diferentes categorias sociais, desta forma é necessário considerar fatores políticos, econômicos, culturais e bióticos para a análise dos processos de degradação do ambiente (MAZZEI, 2007).

A nascente está localizada em área de preservação permanente, estando mantida em seu entorno um raio de 50 metros sem ocupação, de acordo com a legislação (Figura 2). Entretanto, a área de preservação não impediu a degradação ambiental, uma vez que foi possível identificar a existência de vegetação exóticas invasoras entre a vegetação nativa em estágio inicial de regeneração. Além disso, a APP não é isolada e o acesso de é irrestrito, muitas vezes servindo de depósito de resíduos.

A distância entre a nascente e as residências mais próximas é de aproximadamente 70 m, não apresentando despejo superficial de esgoto sanitário. No entanto, o loteamento não possui sistema de 
Revista Tecnologia e Ambiente, v. 25, 2019, Criciúma, Santa Catarina/SC ISSN Eletrônico 2358-9426 e ISSN

Impresso 1413-8131

coleta e tratamento de esgoto, desta forma o esgoto sanitário é destinado a fossas sépticas possibilitando a contaminação das águas subterrâneas.

Após as análises na nascente e a somada pontuação dos parâmetros macroscópicos da nascente (Tabela 3), obteve-se a somatória de 23 pontos. Ficando estabelecido o Índice de Impacto Ambiental em Nascentes classe E, péssimo estado de conservação, acordo com a metodologia de Gomes et al. (2005).

\section{CONCLUSÃO}

Os resultados evidenciaram a ocorrência de alguns impactos causados ao meio hídrico avaliado. Os parâmetros físico-químicos como condutividade elétrica, DQO e DBO não atenderam os limites da legislação.

As análises microbiológicas indicaram a presença de Coliformes Termotolerantes e Escherichia coli estando em desacordo com a portaria de potabilidade. Além disso, a análise de toxicidade empregando A. Salina indicou certa toxicidade na água da nascente. O Índice de Impacto Ambiental demonstrou péssimas condições de preservação da nascente.

\section{REFERÊNCIAS}

ABNT, Associação Brasileira de normas técnicas. NBR 14339 Água - Determinação de pH - Método eletrométrico. Rio de Janeiro, 1999.

ABNT, Associação Brasileira de normas técnicas. NBR 14340 Água - Determinação da condutividade e da resistividade elétrica. Rio de Janeiro, 1999.

ALMEIDA, R. M. A. A. et al. Qualidade microbiológica do córrego "Ribeirão dos Porcos" no município de Espírito Santo do Pinhal-SP. Engenharia Ambiental, v. 1, n. 1, p. 051-056, 2004.

ALVES, E. C. et al. Avaliação da qualidade da água da bacia do rio Pirapó - Maringá, Estado do Paraná, por meio de parâmetros físicos, químicos e microbiológicos. Acta Scientiarum Technology, Maringá, v. 30, n. 1, pag. 39-48, 2008.

APHA. Standard Methods for the examination of water and wastewater. 20. ed. Washington DC: APHA, 1998.

APHA. Standard Methods for the examination of water and wastewater. 23. ed. Washington DC: APHA, 2017.

BAHIA, V. E. et al. Caracterização hidrogeoquímica das águas subterrâneas nas áreas de abrangência do reservatório de abastecimento público do Utinga - Belém (PA). Revista Águas Subterrâneas, v.25, n.1, p.43$56,2011$.

BELIZÁRIO, W. S. Avaliação da qualidade ambiental de nascentes em áreas urbanas: um estudo sobre bacias hidrográficas do município de aparecida de Goiânia/go. Revista Mirante, v. 8, n. 1, 2015.

BORGES, M. J.; GALBIATTI, J. A.; FERRAUDO, A. S.; Monitoramento da qualidade hídrica e eficiência de interceptores de esgoto em cursos d'água urbanos da bacia hidrográfica do Córrego Jaboticabal. Revista Brasileira de Recursos Hídricos. v. 8, n. 2, p. 161-171, 2003.

BRAGA, F. P. Validação de desempenho de uma estação de tratamento de água do Município de Juiz de fora - MG. 70 f. 2014. Trabalho de Conclusão de Curso (Engenharia Sanitária e Ambiental) - Universidade Federal de Juiz de Fora. Juiz de Fora, 2014.

BRASIL. Lei 12.651, de 25 de maio de 2012. Dispõe sobre a proteção da vegetação nativa; altera a Lei no 9.938, de 31 de agosto de 1981; e dá outras providências. Legislação brasileira, Brasília, 25 de mai. 2012.

BRASIL. Ministério Do Meio Ambiente. Conselho Nacional Do Meio Ambiente, CONAMA. Resolução ${ }^{\circ}$ 357 de 17 de março de 2005. Dispõe sobre a classificação dos corpos de água e diretrizes ambientais para o 
seu enquadramento, bem como estabelece as condições e padrões de lançamento de efluentes, e dá outras providências. Diário Oficial da União. Brasília, 18 mar. 2005.

BRASIL. Ministério Do Meio Ambiente. Conselho Nacional Do Meio Ambiente, CONAMA. Resolução ${ }^{\circ}$ 396 de 07 de abril de 2008. Dispõe sobre a classificação e diretrizes ambientais para o enquadramento das águas subterrâneas e dá outras providências. Diário Oficial da União. Brasília, 07 abr. 2008.

BRASIL. Ministério Do Meio Ambiente. Conselho Nacional Do Meio Ambiente, CONAMA. Resolução ${ }^{\circ}$ 430 de 13 de maio de 2011. Dispõe sobre as condições e padrões de lançamento de efluentes, complementa e altera a Resolução CONAMA no 357. Diário Oficial da União. Brasília, 16 mai. 2011.

BRASIL. Portaria no 2.914 de 12 de dezembro de 2011. Ministério da Saúde. Brasília, 2011.

CETESB, Companhia Ambiental do Estado de São Paulo. Significado Ambiental e Sanitário das variáveis de qualidade das águas e dos sedimentos e metodologias analíticas e de amostragem. São Paulo: CETESB, 2009.

CHAPMAN, D.; KIMSTACH, V. Water quality assessment: a guide to the use of biota, sediments and water in environmental monitoring. Londres: UNESCO/ WHO/UNEP, Cap. 3, 60 p. 1996. Disponível em: <http://www.who int/water_sanitation_health/resources/wqa/en/>. Acesso em: 04/05/18.

DANELUZ, D.; TESSARO, D. Padrão físico-químico e microbiológico da água de nascentes e poços rasos de propriedades rurais da região sudoeste do Paraná. Arquivos do Instituto Biológico, v. 82, p. 01-05, 2015.

DEZOTTI, M. Processos e técnicas para o controle ambiental de efluentes líquidos. Rio de Janeiro: Epapers, 2008.

FIGUEIREDO, R. F. et al. Avaliação da toxicidade e análise microbiológica de águas minerais de Caxambu MG. Revista pesquisa inovação farmacêutica, v.5, n.1, p.23-30, 2013.

GraphPad Software Inc. GraphPad Instat, version 3.10: Project planning software. GraphPad Software Inc, 2018. Statistic software.

GUERRA, R. Ecotoxicological and chemical evaluation of phenolic compounds in industrial effluents. Chemosphere, v. 44, n. 8, p. 1737-1747, 2001.

GOMES, P. M.; MELO. C.; VALE, V. S. Avaliação dos impactos ambientais em nascentes na cidade de Uberlândia - MG: análise macroscópica. Sociedade \& Natureza, Uberlândia, 17 (32). p.103-120. 2005.

GOOGLE. Google Earth. Version 7.3.1. 2016. Nota (Perímetro urbano de Francisco Beltrão-PR). Disponível em: <https://www.google.com/maps/@-26.06013,-53.02578,2816m/data=!3m1!1e3>. Acesso em: 05 de maio de 2018.

IBGE, Instituto Brasileiro de Geografia e Estatística. Censo Demográfico. 2010.

IBGE, Instituto Brasileiro de Geografia e Estatística. Censo Demográfico. 2017.

LIBÂNIO, M. Fundamentos de qualidade e tratamento de água. 3.ed. São Paulo: Editora Átomo, 2010.

MACEDO, J. A. B. Introdução à química ambiental. CRQ/MG. Juiz de Fora, 2006. 1028p.

MACHADO, W.C.P. indicadores da qualidade da água na bacia hidrográfica do rio Pato Branco. Tese (Doutorado em Geologia), UFPR, Curitiba, 2006.

MAZZEI, K. et al. Áreas verdes urbanas, espaços livres para o lazer. Revista Sociedade \& Natureza, 19 (1), p 33-43, jun., 2007.

MEDEIROS, M. A. C. et al. Apostila de química sanitária e laboratório de saneamento II. Curso de Tecnologia em Saneamento Ambiental, UNICAMP. Limeira, 2006. 49p.

ROCHA, R. R. A.; MARTIN, E. S. Análise preliminar do estado ambiental do córrego água da lavadeira, Rancharia-SP: Análise física e química da água. Revista Eletrônica AGB-TL, v. 1, n. 2, p. 116-130, 2005. RODRIGUES, L. C. A. Toxicidade da água e sedimento do córrego do pântano, ALFENASMG: um estudo temporal e espacial. 2012. Dissertação (Mestrado em Ecologia e Tecnologia Ambiental) Universidade Federal de Alfenas. Alfenas, 2012.

SILVA, A. C.; DOURADO, J. C.; KRUSCHE, A. V.; GOMES, B. M. Impacto físico-químico da deposição de esgotos em fossas sobre as águas de aqüífero freático em Jiparaná- RO. Revista de estudos ambientais, v.11, n. 2, p. 101-112, jul./dez. 2009.

SPERLING, M. V. Introdução à qualidade das águas e ao tratamento de esgotos. $3^{\mathrm{a}}$ Edição. Princípios do tratamento biológico de águas residuárias. Editora da Universidade Federal de Minas Gerais - UFMG - Belo Horizonte, 2005.

TOLEDO, L. G.; NICOLELLA, G. Índice de qualidade de água e microbacia sob uso agrícola e urbano, v. 59, n1, p. 181-186, jan./mar. 2002.

TOZZO, R. A; GONÇALVES, E. A. Análise físico-química da água do Riacho Japira, localizado no município de Apucarana-PR. Revista Meio Ambiente e Sustentabilidade, v. 7, n. 3, p. 296-307, 2014. 
TUCCI, C. E. M. Gestão integrada das águas urbanas. Revista de Gestão de Água da América Latina, v. 5, n. 2, p. 71-81, 2008.

VASCO, A. N.; BRITTO, F. B.; PEREIRA, A. P. S.; MÉLlO JÚNIOR, A. V. M.; GARCIA, C. A. B.; NOGUEIRA, L. C. Avaliação espacial e temporal da qualidade da água na sub-bacia do rio Poxim, Sergipe, Brasil. Ambi-Agua, v. 6, n. 1, p. 118-130, 2011.

ZANIN, P.R.; BONUMÁ, N. B.; CHAFFE, P.L.B. Características hidrogeológicas de nascentes situadas em diferentes modelados de relevo. XX Simpósio Brasileiro de Recursos Hídricos - água desenvolvimento econômico e sócio ambiental. Associação Brasileira de Recursos Hídricos. Bento Gonçalves/RS. 2013. 